\title{
Minimizing Mutually Coupled Switched Reluctance Machine's Stator Volume by Stator Yoke Optimization
}

\author{
C. SAHIN, M. KARACOR and A. E. AMAC
}

\begin{abstract}
In parallel with the increased production of electric vehicles, the research on electric motors has become very popular. Switched Reluctance Machines (SRMs) have been widely preferred in these investigations. Mutually Coupled Switched Reluctance Machine (MCSRM) has higher torque performances than conventional SRMs have. In this study, it is aimed to reduce the weight of MCSRM by geometric arrangement. For this purpose, the MCSRM's stator yoke is minimized without deteriorating the flux distribution. Various geometrical changes are performed on the stator yoke of the MCSRM. Each of the obtained motor models is magnetostatic analyzed in different currents by finite-element analysis. From comparison of the results of the analysis, it is seen that the proposed MCSRM models show reduction in the stator volumes between $11.31 \%$ and $14.17 \%$. This reduction leads to a reduction in the overall weight of the MCSRM.
\end{abstract}

Index Terms-Mutually Coupled Switched Reluctance Machine (MCSRM), stator yoke, volume, weight.

\section{INTRODUCTION}

$\mathrm{T}$ HE STUDIES OF advanced traction motors generally focus on efficiency, high power density, higher torque, lower noise, and cost [1]. Permanent magnet (PM) motors have high efficiency, high torque density, and compactness. Because of these features, they are widely used in hybrid and electric vehicles. But, the magnet is a rare element in nature. For this reason, the magnet is still one of the main concerns for hybrid and electric vehicle manufacturers. In this case,

CIHAN SAHIN, is with Department of Control and Automation of University of Bilecik Seyh Edebali, Bilecik, Turkey, (e-mail: cihan.sahin@bilecik.edu.tr).

iD https://orcid.org/0000-0001-6430-7827

MEVLUT KARACOR, is with Department of Mechatronic Engineering of University of Celal Bayar, Turgutlu, Turkey, (e-mail: mevlut.karacor@cbu.edu.tr).

(iD https://orcid.org/0000-0001-5408-9117

AYSE ERGUN AMAC, is with Department of Energy Systems Engineering of University of Kocaeli, Kocaeli, Turkey, (e-mail: ayseergun@kocaeli.edu.tr).

iD https://orcid.org/0000-0003-3215-0129

Manuscript received December 27, 2018; accepted April 13, 2019. DOI: $\underline{10.17694 / \text { bajece. } 503752}$
SRMs can be considered as one of the alternative solutions [23].

SRMs consist of a stator with windings and a rotor with saliency. They have no winding or permanent magnet on rotor [4-5]. Since SRMs do not need PM, they have low cost and work even in high temperature conditions created by internalcombustion engines [6]. SRMs are ideal for adjustable speed applications because of these properties [7]. They have stronger structure compared to PM motors, although they are produced simpler and at cheaper cost [8]. Although PM motors are preferred for specific applications, they might not be cost effective for mass production in certain applications [9]. SRMs also offer high efficiency and extended-speed constant power operation [10]. Because of all these advantages, SRMs are useful and attractive for electric vehicles as well as they have high competitive power in transportation applications [11-14].

High torque ripple is one of the major disadvantages of SRMs due to their high nonlinearity of torque production [1516]. For the purpose of the torque ripple reduction, the researchers have improved the motor magnetic design and have used complex control algorithms for the motor [17-18]. In recent years, many studies have been devoted to different rotor or stator configurations with specific properties to improve the performance of SRMs [19-20].

In conventional SRMs, the windings are located on opposite poles of the stator. They are connected as series to form a phase of the machine. The asymmetric-half-bridge type converter is commonly used in SRM drives [21]. When a suitable phase in the machine is excited with DC voltage, the moving rotor begins to rotate in the direction that reduces the reluctance of the magnetic circuit. The continuity in turning of the rotor is obtained by energizing the phases respectively. Fig. 1 shows the 3-phase, 6/4-pole stator-rotor structure of conventional SRMs.

Torque characteristics of SRM are highly nonlinear and dependent on the rotor position and phase current [22]. SRMs operate based on reluctance torque and have a "minimum reluctance" rule. In addition, they cannot be easily applied to traditional power equations [23]. In SRMs, as the air gap between the stator and rotor pole heads increases, the reluctance of the magnetic circuit also grows. The machine structure tends to reduce this high reluctance and produces a torque for this. With the production of torque, the stator and rotor pole heads close up. As a result, the reluctance of the magnetic circuit is reduced. Thus, as a result of the request to 
reduce the reluctance, the continuity of the machine torque is generated.

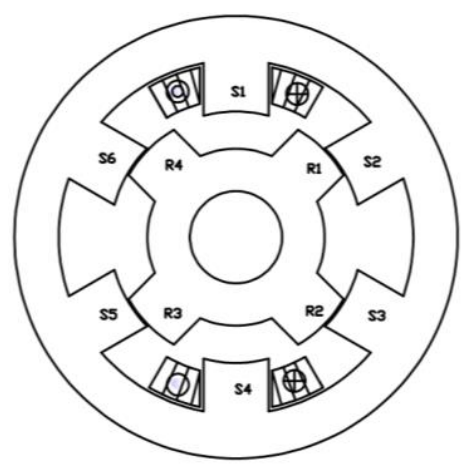

Fig.1. Conventional SRM

The winding structure of conventional SRMs is short pitched. Mecrow has changed the winding structure of classical SRM and placed windings as full pitched instead of short pitched [24]. It is called the 'fully-pitched SRM'. The electromagnetic (EM) torque in fully-pitched SRM is formed entirely by the mutual inductance formed between the phases [25-26]. The fully-pitched SRMs are also known as MSCRM and are named accordingly [26]. MCSRMs could have 25\% more output torque than conventional SRM could have [25]. These machines can be used in a variety of applications, using conventional 6 switch inverter or the asymmetric half-bridge converter [26].

In this study, the performance of MCSRM based on stator volume is proposed. For this aim, a MCSRM prototype and five different MCSRM models with modified stator yoke are developed. The only difference between the proposed models is the geometric arrangements on the stator yoke. The other parameters of the machine are kept constant. Therefore, they have not been observed in this study.

\section{STRUCTURE OF MCSRM}

The phase coupling in the conventional SRMs is very small and can be neglected, but it cannot be neglected for MCSRM. Therefore, the phases are coupled by the nature of MSCRM operation [27]. The torque in MCSRMs is produced by the changing of the mutual coupling that occurs between phases according to the rotor position [25]. As a result; torque is produced by energizing more than one phase at the same time. Fig. 2 shows the structure of MCSRM.

In SRMs, torque is produced by controlling each phase independently. Thus, torque generation is transferred from the active phase to the other phase. Consequently, torque vibrations become important in these switching moments [28]. Eq. (1) shows the general torque expression in a SRM.

$$
\begin{aligned}
& T=\frac{1}{2} i_{a} i_{b} \frac{\partial M_{a b}}{\partial \theta}+\frac{1}{2} i_{b} i_{c} \frac{\partial M_{b c}}{\partial \theta}+\frac{1}{2} i_{c} i_{a} \frac{\partial M_{c a}}{\partial \theta}+ \\
& \frac{1}{2} i_{a}{ }^{2} \frac{\partial L_{a}}{\partial \theta}+\frac{1}{2} i_{b}{ }^{2} \frac{\partial L_{b}}{\partial \theta}+\frac{1}{2} i_{c}{ }^{2} \frac{\partial L_{c}}{\partial \theta}
\end{aligned}
$$

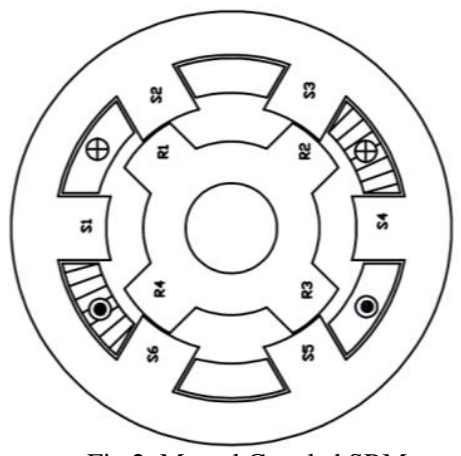

Fig.2. Mutual Coupled SRM

Where $T$ is the total torque; $i_{a}, i_{b}, i_{c}$ are the phase currents; $\mathrm{L}_{\mathrm{a}}, \mathrm{L}_{\mathrm{b}}, \mathrm{L}_{\mathrm{c}}$ are the phase inductances; and $\mathrm{M}_{\mathrm{ab}}, \mathrm{M}_{\mathrm{bc}}, \mathrm{M}_{\mathrm{ac}}$ are the mutual inductances between the phases. Since the torque in MCSRM is produced with the mutual inductance between the phases and self inductances are neglected in MCSRMs, the torque can be denoted as in equation (2) [26].

$$
T=\frac{1}{2} i_{a} i_{b} \frac{\partial M_{a b}}{\partial \theta}+\frac{1}{2} i_{b} i_{c} \frac{\partial M_{b c}}{\partial \theta}+\frac{1}{2} i_{c} i_{a} \frac{\partial M_{c a}}{\partial \theta}
$$

Since two phases are active in MCSRM (assume phase ' $a$ ' and phase ' $b$ ' are active, and phase ' $c$ ' is passive), Eq. (2) turns into Eq. (3).

$$
T=\frac{1}{2} i_{a} i_{b} \frac{\partial M_{a b}}{\partial \theta}
$$

\section{DESIGN OF MCSRM}

The only feature which distinguishes the five proposed MCSRM models from the basic MCSRM model is the stator yoke structures. For the comparison of the machines, the basic model MCSRM is called MCSRM-0 in this study. Fig. 3 denotes the geometric structure of the 6/4 MCSRM-0.

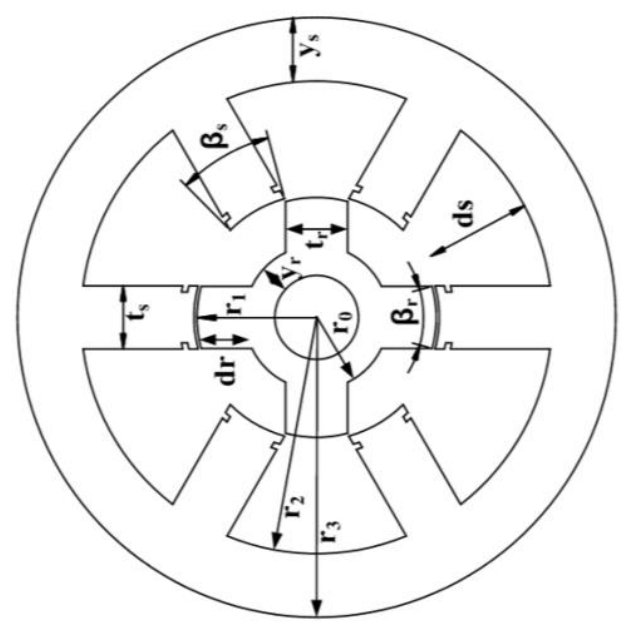

Fig.3. Geometric structure of the MCSRM-0

Where $\beta_{\mathrm{r}}$ is the rotor pole arc (degree), $\beta_{\mathrm{s}}$ is the stator pole $\operatorname{arc}$ (degree), $t_{\mathrm{s}}$ is the stator pole width, $t_{\mathrm{r}}$ is the rotor pole 
width, $d_{s}$ is the stator pole height, $d_{r}$ is the rotor pole height, $y_{s}$ is the stator yoke thickness, $\mathrm{y}_{\mathrm{r}}$ is the rotor yoke thickness, and $\mathrm{g}$ is the air-gap length. Table 1 presents the dimensions of the 6/4 MCSRM-0.

TABLE I

GEOMETRIC DIMENSIONS OF THE MCSRM-0

\begin{tabular}{|c|c|c|c|}
\hline Symbol & Value & Symbol & Value \\
\hline $\mathrm{r}_{0}$ & $12.00(\mathrm{~mm})$ & $\mathrm{y}_{\mathrm{s}}$ & $10.60(\mathrm{~mm})$ \\
\hline $\mathrm{r}_{1}$ & $20.00(\mathrm{~mm})$ & $\mathrm{yr}_{\mathrm{r}}$ & $05.00(\mathrm{~mm})$ \\
\hline $\mathrm{r}_{2}$ & $39.40(\mathrm{~mm})$ & $\mathrm{d}_{\mathrm{s}}$ & $18.90(\mathrm{~mm})$ \\
\hline $\mathrm{r}_{3}$ & $50.00(\mathrm{~mm})$ & $\mathrm{d}_{\mathrm{r}}$ & $08.00(\mathrm{~mm})$ \\
\hline $\mathrm{t}_{\mathrm{s}}$ & $10.50(\mathrm{~mm})$ & $\beta_{\mathrm{r}}$ & $30^{0}$ \\
\hline $\mathrm{t}_{\mathrm{r}}$ & $10.50(\mathrm{~mm})$ & $\beta_{\mathrm{s}}$ & $30^{0}$ \\
\hline $\mathrm{g}$ & $0.50(\mathrm{~mm})$ & depth & $40.00(\mathrm{~mm})$ \\
\hline
\end{tabular}

\section{PROPOSED MCSRM STATOR YOKE MODELS}

In the study, first, the MCSRM-0 is magnetostatic analyzed with 2D finite element method (FEM) at different currents. In addition, flux density is examined. 2D (FEM) analysis is sufficient to obtain the required results [29]. Geometric regulation is realized in regions where flux density is decreased. For the comparison of the machines, proposed models are called MCSRM-1, MCSRM-2, MCSRM-3, MCSRM-4, and MCSRM-5 respectively. The proposed five stator yoke models are shown in Fig.4.
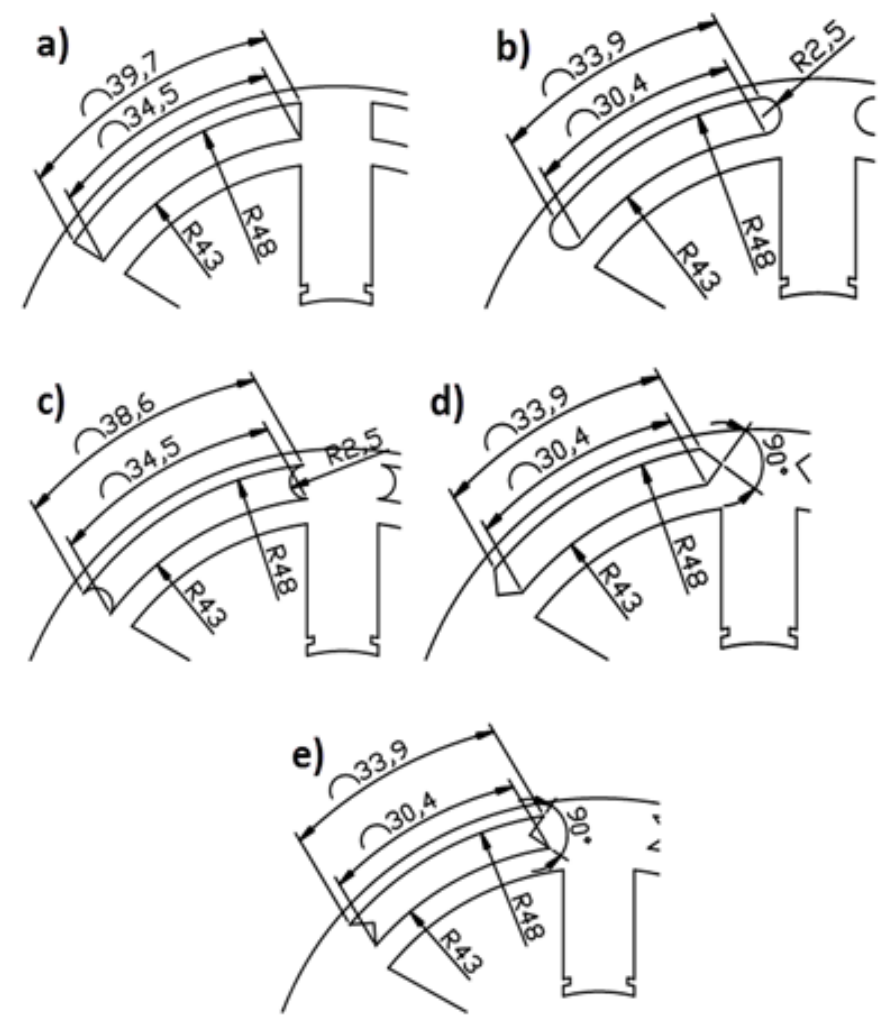

Fig.4. Proposed stator yoke models a) MCSRM-1, b) MCSRM-2, c) MCSRM-3, d) MCSRM-4, and e) MCSRM-5

\section{SUBMISSION RESULTS AND DISCUSSIONS}

Each of the obtained motor models is analyzed at different currents through the 2D finite-element analysis. Firstly, the MCSRM-0 is analyzed for the comparison of the proposed models. The curves of mutual inductance and torque obtained from the analysis results are plotted for MCSRM- 0 as shown in Fig.5. The distribution of the flux for MCSRM-0 at 10Amps is denoted in Fig.6.
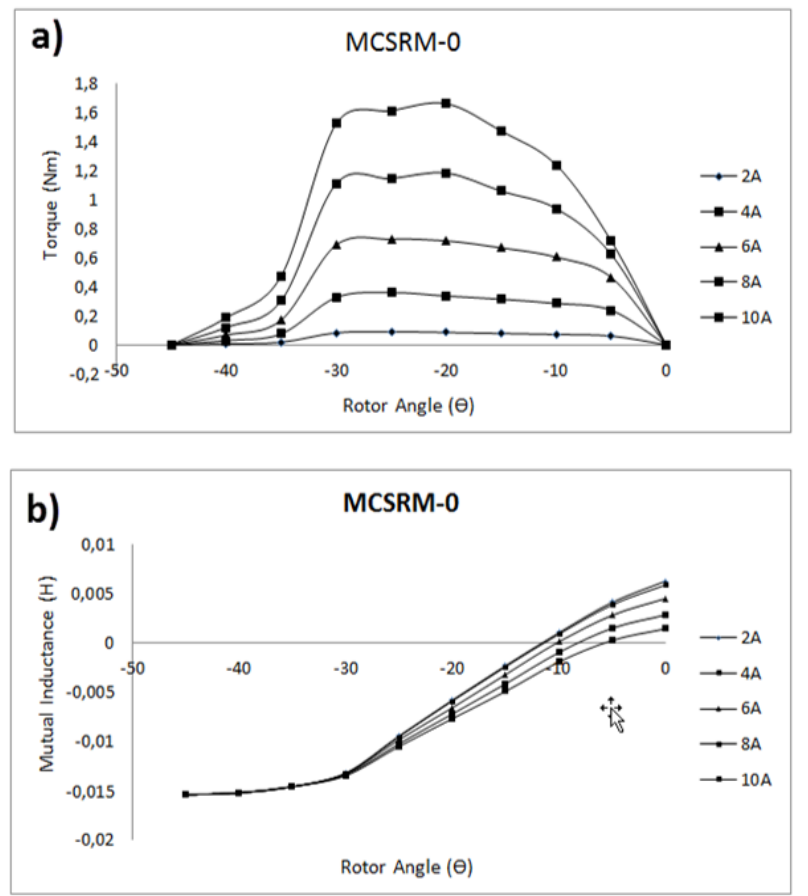

Fig.5. Curves of MCSRM-0 a) Torque curves of MCSRM- 0 and b) Mutual inductance curve of MCSRM-0

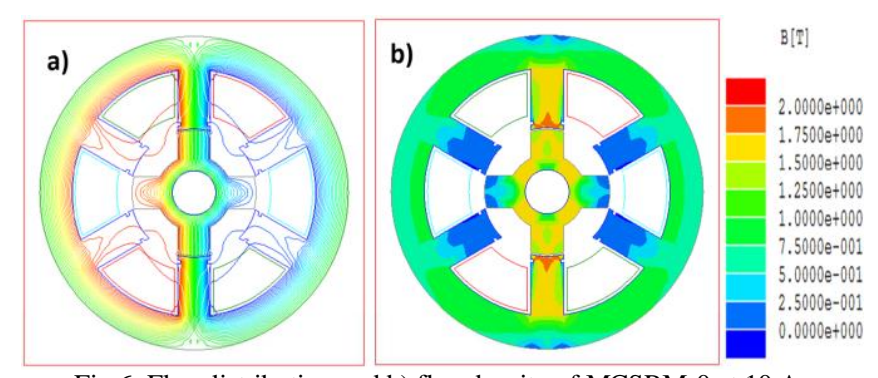

Fig.6. Flux distribution and b) flux density of MCSRM-0 at 10 Amps

The proposed MCSRM-1...MCSRM-5 are obtained through an optimization study on MCSRM- 0 . The same rotor is used in all MCSRMs and just a simple modification is performed on its stator yoke. It is presented in Fig.4. The geometric arrangements of the proposed MSCRM models are based on the flux distribution of the basic model (MCSRM-0). The flux distribution of the MCSRM-0 in Fig.6 is dealt with and intensive regions are determined. In regions where the flux density shows decrease, the thickness of the stator yoke is thinned and MCSRM-1 model is formed. In the MCSRM-1 model, the ends of this region, which is extracted from the stator yoke region, are cut flat. The end points of this region are near the stator pole. Therefore, the 'flux linkages' can occur 
at the end points of the region. For this reason, the end points of these regions are studied in five different basic geometric shapes such as straight, convex, concave, outer triangle, and inner triangle. According to the results of the analysis, despite the five different geometric structures, flux distributions and flux densities are very close to each other.

The MCSRM- 0 and the five proposed models are analyzed in the range of 1-10 amps with 1 amp step. In order to compare the proposed models to the performance of MCSRM0 , the curves obtained from the analyses performing at $5 \mathrm{Amps}$ and $10 \mathrm{Amps}$ are used. The purpose of comparing the $5 \mathrm{Amps}$ and 10 Amps can be seen clearly on the graph that similar results are obtained in different currents. The comparison of the torque curves of the five proposed models with the torque curves of MCSRM-0 is shown in Fig.7.

When the torque curves of the MCRSM- 0 and the proposed models obtained from the analyses are compared, they show a very similar characteristic to each other. Fig.7-a shows the comparison of the torque curves of MCSRM- 0 and MCSRM- 1 at 5 Amps and 10 Amps. When the $T_{\max }$ value of the MCSRM0 is $1.66 \mathrm{Nm}$ at $10 \mathrm{Amps}$, the $\mathrm{T}_{\max }$ value of MCSRM-1 is 1.56 $\mathrm{Nm}$. Similarly, when the $\mathrm{T}_{\max }$ value of MCSRM- 0 is $0,55 \mathrm{Nm}$ at 5 Amps, the $T_{\max }$ value of MCSRM- 1 is $0,52 \mathrm{Nm}$. When the $\mathrm{T}_{\max }$ values are compared with the analysis results obtained at 5 Amps and $10 \mathrm{Amps}$, it can denote that the difference is very small. The torque characteristics of both models are also quite similar.

Fig.7-b shows the comparison of the torque curves of MCSRM- 0 and MCSRM-2 at 5 Amps and 10 Amps. The $T_{\max }$ values of MCSRM-2 are $1.57 \mathrm{Nm}$ at 10 Amps and $0.52 \mathrm{Nm}$ at 5 Amps. When $T_{\max }$ values are evaluated, $T_{\max }$ values of MCSRM-2 and MCSRM- 0 are very close to each other. The torque characteristics of both models are also quite similar.

When the torque curves of MCSRM-3, MCSRM-4, and MCSRM-5 in Fig.7-c-d-e are evaluated, there are very small decreases in $\mathrm{T}_{\max }$ values compared to MCSRM- 0 as in the previous three models. The torque characteristic of all three models is also very close to the MCSRM-0. When all torque curves are evaluated together, it is seen that the peak values and the characteristic curves of all the models are very close to each other.

When the flux distributions of the basic model and the proposed MSCRM models are evaluated, it appears that the values are very small. The flux in regulated regions completes the flow from the stator yoke region near the coil which has a lower resistance compared to the high resistance of the air. Thus, the density of the flux increases in those regions. The flux distributions of the proposed models are given in Fig.8. The density of the flux in the near-winding region seems to be more intense when compared to the MCSRM-0`s given in Fig.6. Since the total flux density does not change too much, the engine performance is not adversely affected. The distribution of the flux for proposed MCSRM models at 10 Amps is shown in Fig.8.
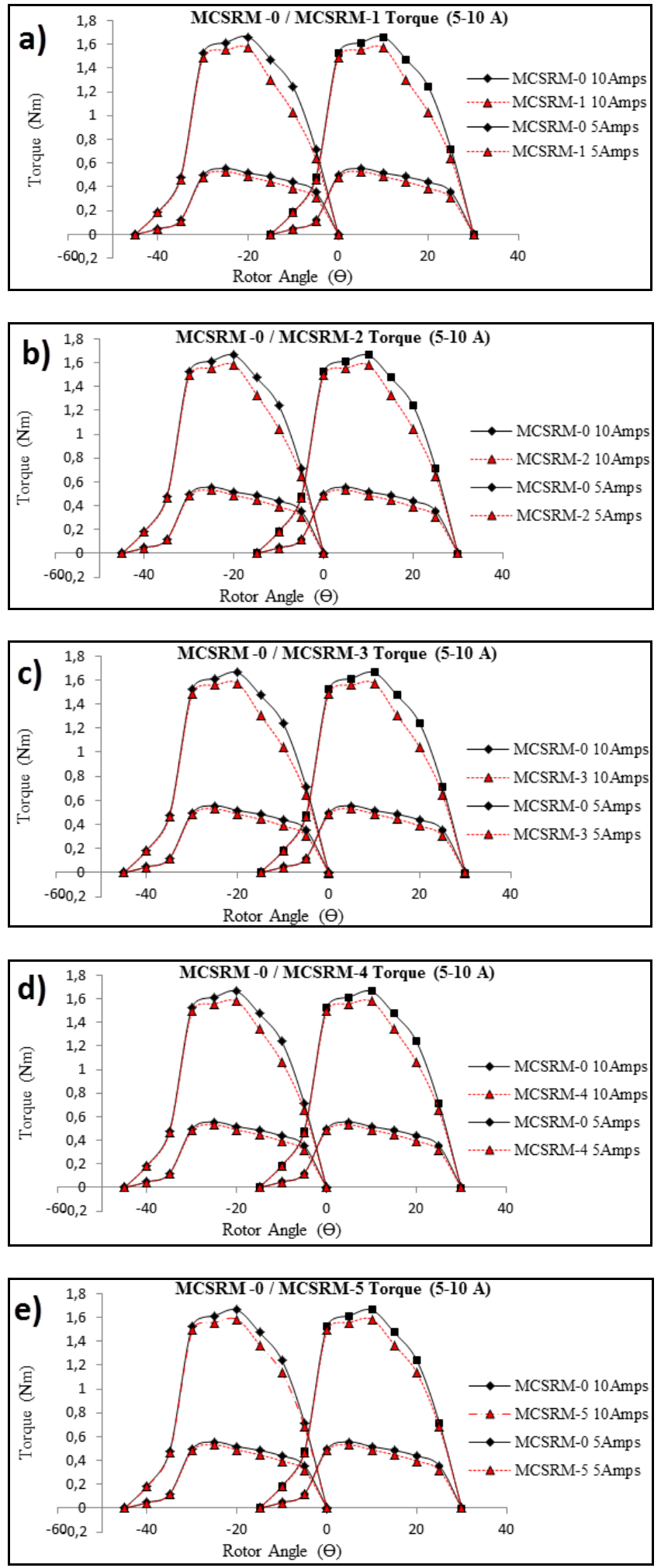

Fig.7. Comparisons of the curves of torque a) MCSRM-0 and MCSRM- 1 , b) MCSRM-0 and MCSRM-2, c) MCSRM- 0 and MCSRM-3, d) MCSRM-0 and MCSRM-4, and e) MCSRM-0 and MCSRM-5

In the proposed models, the flux which flows on the stator yoke is forced to flow through a narrow path by being compressed. Thus, there is no significant change in the total flux value. The small changes in the torque values of the proposed models are due to the resistance difference of the geometric regions. Therefore, there are very small differences 
in the areas of the proposed geometric regulations.
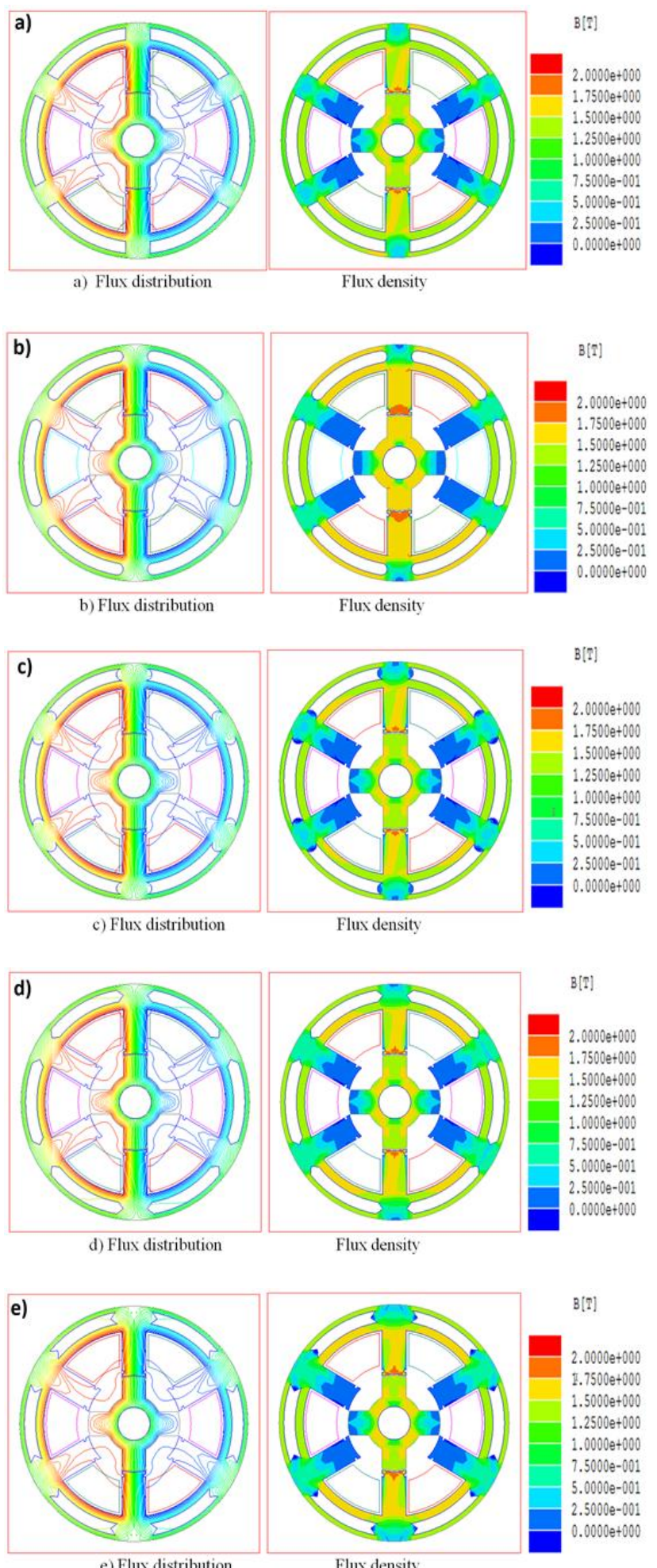

Fig.8. Flux distribution and Flux density of recommended MCSRMs a) MCSRM-1, b) MCSRM-2, c) MCSRM-3, d) MCSRM-4, and e) MCSRM-5

The torque in MCSRM is produced depending on mutual inductance. Hence, the mutual inductance curves of the proposed models are evaluated and given in Fig.9. The mutual inductance curves of the five proposed models are quite close when compared to the mutual inductance curves of MCSRM-0 given in Fig.9. The close proximity of mutual inductance curves are proofs of the proximity of the motor torque curves.

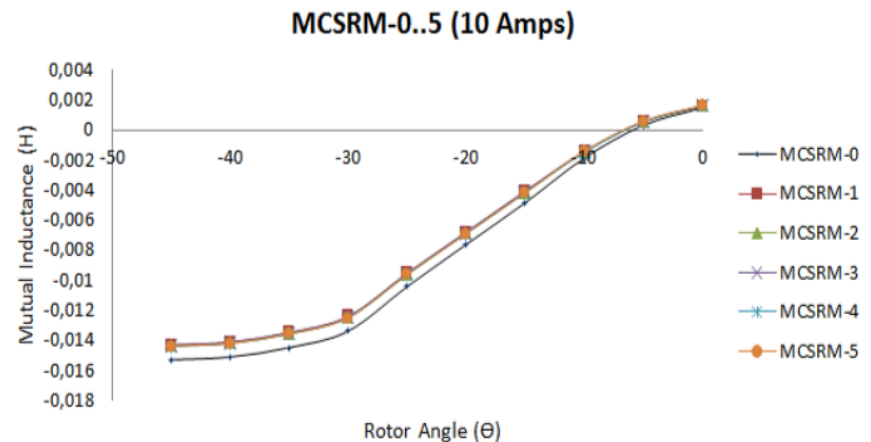

Fig.9. Proposal structure of Salesbary Screen Mutual inductance curves of proposed MCSRMs and MCSRM-0

The average torque value and torque ripple ratio are also very important for the performance comparison of an electric machine. For this reason, the geometric regulations in electric machines should not adversely affect the machine performance. In this study, the average torque values and torque ripple ratios of the proposed models are calculated and compared with the basic model.

The difference between the maximum and minimum instantaneous torque expressed as a percentage of average torque at steady-state operation is called torque ripple [30].

$$
T_{\text {ripple }}=\frac{T_{\text {ins(max) }}-T_{\text {ins(min;) }}}{T_{\text {avg }}} \times 100 \%
$$

The average torque can be derived mathematically through integration:

$$
T_{a v g}=\frac{1}{T} \int_{0}^{T} T_{i n s} d t
$$

Torque ripple ratios of all models are calculated using Equations (4) - (5) at 5 Amps and 10 Amps. The basic model MCSRM- 0 has a value of $T_{\text {avg }}=1,13 \mathrm{Nm}$ at 10 Amps. On the other hand, in the proposed models, $T_{\text {avg }}$ decreases to $1.08 \mathrm{Nm}$ at 10 Amps. The average torque difference at 10 Amps of the MCSRM-0 and of the proposed models is about $0.05 \mathrm{Nm}$. This difference decreases to $0.03 \mathrm{Nm}$ at $5 \mathrm{Amps}$. Since MCSRMs have high torque density, these values are quite small and negligible. The average torques and torque ripples rates of all MCSRM models are given in Table 2.

For the calculation of torque ripple, the instantaneous torque and average torque are determined. The obtained values at 10 Amps are replaced in (5). As a result, the torque ripple of the basic model MCSRM-0 is $46.2 \%$. For the proposed model MCSRM-1, the attained values at 10 Amps are replaced in (5). Thus, the torque ripple is $44.9 \%$. The results for the torque ripple rates of proposed MCSRM models are rather lower, yet acceptable. Moreover, in the arranged regions of the proposed models, the air circulation contributes to the cooling of the machine. 
TABLE II

THE AVERAGE TORQUES AND TORQUE RIPPLES RATES OF ALL MCSRM MODELS

\begin{tabular}{|c|c|c|c|c|c|c|}
\hline & $\begin{array}{c}\text { MC } \\
\text { SRM-0 }\end{array}$ & $\begin{array}{c}\text { MC } \\
\text { SRM-1 }\end{array}$ & $\begin{array}{c}\text { MC } \\
\text { SRM-2 }\end{array}$ & $\begin{array}{c}\text { MC } \\
\text { SRM-3 }\end{array}$ & $\begin{array}{c}\text { MC } \\
\text { SRM-4 }\end{array}$ & $\begin{array}{c}\text { MC } \\
\text { SRM-5 }\end{array}$ \\
\hline $\begin{array}{c}10 \mathrm{~A} \\
\mathrm{~T}_{\text {avg }} \\
(\mathrm{Nm})\end{array}$ & 1,13 & 1,08 & 1,09 & 1,08 & 1,08 & 1,09 \\
\hline $\begin{array}{c}10 \mathrm{~A} \\
\mathrm{~T}_{\mathrm{rp}} \\
(\%)\end{array}$ & 46,2 & 44,9 & 45,8 & 46,5 & 46,5 & 45,8 \\
\hline $\begin{array}{c}5 \mathrm{~A} \\
\mathrm{~T}_{\text {avg }} \\
(\mathrm{Nm})\end{array}$ & 0,4 & 0,37 & 0,37 & 0,37 & 0,38 & 0,38 \\
\hline $\begin{array}{c}5 \mathrm{~A} \\
\mathrm{~T}_{\mathrm{rp}} \\
(\%)\end{array}$ & 37,5 & 38,6 & 38,6 & 40,5 & 39,4 & 39,4 \\
\hline
\end{tabular}

Without minimizing the stator volume while maintaining the motor performance, the improvements at torque ripple are not very important. The improvements obtained from the stator volumes for the proposed MCSRM models are given in Table 3. Small changes in torque performance are negligible when compared to the weight obtained from the stator volume.

TABLE III COMPARISON OF MCSRM S STATOR VOLUMES

\begin{tabular}{|c|c|c|c|c|c|c|}
\hline & $\begin{array}{c}\text { MC } \\
\text { SRM-0 }\end{array}$ & $\begin{array}{c}\text { MC } \\
\text { SRM-1 }\end{array}$ & $\begin{array}{c}\text { MC } \\
\text { SRM-2 }\end{array}$ & $\begin{array}{c}\text { MC } \\
\text { SRM-3 }\end{array}$ & $\begin{array}{c}\text { MC } \\
\text { SRM-4 }\end{array}$ & $\begin{array}{c}\text { MC } \\
\text { SRM-5 }\end{array}$ \\
\hline $\begin{array}{c}\text { Volume } \\
\left(\mathrm{cm}^{3}\right)\end{array}$ & 314,16 & 269,62 & 270,91 & 274,4 & 272,62 & 278,62 \\
\hline $\begin{array}{c}\text { Reduce } \\
(\%)\end{array}$ & & 14,17 & 13,76 & 12,65 & 13,22 & 11,31 \\
\hline
\end{tabular}

Owing to the proposed geometric arrangements, the volume of the basic model MCSRM-0 is decreased from $314.16 \mathrm{~cm}^{3}$ to $269.69 \mathrm{~cm}^{3}$. When the values are generalized as a percentage, the stator volume decreases between $11.31 \%$ and $14.17 \%$ by stator yoke optimization. Depending on the density of the material used in the manufacture of the stator, the stator weight also decreases significantly. A lighter MCSRM, which provides near-optimal performance in applications such as electric vehicles, is more preferable than the basic model. One of the important points to be considered here is the negative strenght on the stator yoke. In order to avoid this situation, stator housing should be considered.

\section{CONCLUSION}

In this study, an approach is proposed for reducing the weight of MCSRM without loss of performance. For this purpose, some modifications have been made to the geometry of the basic model of designed MCSRM. The basic model and all proposed models are the same except for the changes made to the stator yoke. The geometric arrangements on the stator yoke are carried out in regions where the flux density shows a decrease. Thus, the loss of flux is prevented. All models are analyzed and the results of the proposed models are compared with the basic model at 5 Amps and 10 Amps. Due to the proposed geometric stator yoke models, the motor stator volume decreases between $11.31 \%$ and $14.17 \%$. Further, an additional torque ripple does not occur and the torque characteristic is not degraded. In the proposed models, the flux flows over the narrowed region through the stator. These regulations also support air circulation. As a result, the user can use a more lightweight MSCRM. By this advantage, it will bring great benefits especially to electric vehicle works. In future research, the copper losses of the models can be studied, and the advantages and disadvantages of the models can be evaluated. As a result, a lightweight MCSRM with high performance has been proposed for electric vehicles.

\section{REFERENCES}

[1] E. Bostanci, M. Moallem, A. Parsapour, B. Fahimi, "Opportunities and challenges of Switched Reluctance Motor drives for electric propulsion A comparative study", IEEE Transactions on Transportation Electrification, Vol.3, No.1, 2017, pp.58-75.

[2] N. Kurihara, J. Bayless, H. Sugimoto, A. Chiba, "Noise reduction of Switched Reluctance Motor with high number of poles by novel simplified current waveform at low speed and low torque region", IEEE Transactions on Industry Applications, Vol.52, No.4, 2016, pp.3013- 3021.

[3] C. H. T. Lee, K. T. Chau, C. Liu, D. Wu, S. Gao, "Quantitative Comparison and Analysis of Magnetless Machines With Reluctance Topologies Christopher", IEEE Transactions on Magnetics, Vol.49, No.7, 2013, pp.3969-3972.

[4] H. Makino, T. Kosaka, N. Matsui, "Digital PWM-control-based active vibration cancellation for Switched Reluctance Motors", IEEE Transactions on Industry Applications, Vol.51, No.6, 2015, pp.45214530.

[5] J. Kartigeyan, M. Ramaswamy, "Effect of Material Properties on Core Loss in Switched Reluctance Motor using Non-Oriented Electrical Steels", Journal of Magnetics, Vol.22, No.1, 2017, pp.93-99.

[6] K. Kiyota, T. Kakishima, A. Chiba, M.A. Rahman, "Cylindrical Rotor Design for Acoustic Noise and Windage Loss Reduction in Switched Reluctance Motor for HEV Applications", IEEE Transactions on Industry Applications, Vol.52, No.1, 2016, pp.154-162.

[7] A. Shahabi, A. Rashidi, M. Afshoon, S. M. S. Nejad, "Commutation angles adjustment in SRM drives to reduce torque ripple below the motor base speed", Turkish Journal of Electrical Engineering and Computer Sciences, Vol.24, No.2, 2016, pp.669-682.

[8] M. Tursini, M. Villani, G. Fabri, L.D. Leonardo, "A switchedreluctance motor for aerospace application: Design, analysis and results", Electric Power Systems Research, Vol.142, 2017, pp.74-83.

[9] T.S. Chuang, "Acoustic noise reduction of a 6/4 SRM drive based on third harmonic real power cancellation and mutual coupling flux enhancement", Energy Conversion and Management, Vol.3, 2010, pp.546-552.

[10] B. Fahimi, A. Emadi, B.R. Sepe, "A switched reluctance machinebased starter/alternator for more electric cars", IEEE Transactions on Energy Conversion, Vol.19, No.1, 2007, pp.116-124.

[11] H. Cheng, H. Chen, Z. Yang, "Design indicators and structure optimisation of switched reluctance machine for electric vehicles", IET Electric Power Applications, Vol.9, No.4, 2015, pp.319-331.

[12] M. Belhadia, G. Krebsa, C. Marchanda, H. Hannounb, X. Miningera, "Evaluation of axial SRM for electric vehicle application", Electric Power Systems Research, Vol.148, 2017, pp.155-161.

[13] J. Zhu, K. W. E. Cheng, X. Xue, Y. Zou, "Design of a New Enhanced Torque In-Wheel Switched Reluctance Motor With Divided Teeth for Electric Vehicles", IEEE Transactions on Magnetics, Vol.53, No.11, 2017.

[14] S. Sadeghi, M. Mirsalim, "Dynamic Modeling and Simulation of a Switched Reluctance Motor in a Series Hybrid Electric Vehicle", Acta Polytechnica Hungarica, Vol.7, No.1, 2010, pp. 51-71.

[15] J. Kim, Y. Jeong, Y. Jeon, J. Kang, S. Lee, J. Park, "Development of a Switched Reluctance Motor-based Electric AC Compressor Drive for HEV/EV Applications", Journal of Magnetics, Vol.19, No.3, 2014, pp.282-290. 
[16] D. Marcsa, M. Kuczmann, "Design and control for torque ripple reduction of a 3-phase switched reluctance motor", Computers \& Mathematics with Applications, Vol.74, No.1, 2017, pp.89-95.

[17] G. Li, J. Ojeda, S. Hlioui, E. Hoang, M. Lecrivain, M. Gabsi, “ Modification in Rotor Pole Geometry of Mutually Coupled Switched Reluctance Machine for Torque Ripple Mitigating”, IEEE Transactions on Magnetics, Vol.48, No.6, 2012, pp.2025-2034.

[18] M. Asgar, E. Afjei, H. Torkaman, "A New Strategy for Design and Analysis of a Double-Stator Switched Reluctance Motor: Electromagnetics, FEM, and Experiment", IEEE Transactions on Magnetics, Vol.51, No.12, 2015.

[19] W. Ding, Z. Yin, L. Liu, J. Lou, Y. Hu, Y. Liu, "Magnetic circuit model and finite element analysis of a modular switched reluctance machine with E-core stators and multi-layer common rotors", IET Electric Power Applications, Vol.8, No.8, 2014, pp.296-309.

[20] E. Afjei, A. Siadatan, Hossein Torkaman, "Magnetic Modeling, Prototyping, and Comparative Study of a Quintuple-Set Switched Reluctance Motor", IEEE Transactions on Magnetics, Vol.51, No.8, 2015.

[21] X. Cao, Q. Sun, C. Liu, H. Zhou, Z. Deng, "Direct control of torque and levitation force for dual-winding bearingless Switched Reluctance Motor", Electric Power Systems Research, Vol.145, 2017, pp.214 222.

[22] J. E. Stephen, S. S. Kumar, J. Jayakumar, "Nonlinear Modeling of a Switched Reluctance Motor using LSSVM - ABC", Acta Polytechnica Hungarica, Vol.11, No.6, 2014, pp.143-158.

[23] W. Hua, G. Zhao, H. Hua, M. Cheng, "General Power Equation of Switched Reluctance Machines and Power Density Comparison", IEEE Transactions on Industry Applications, Vol.53, No.5, 2017, pp.4298 4307.

[24] X. Sun, Z. Xue, S. Han, X. Xu, Z. Yang, L. Chen, "Design and Analysis of a Novel 16/10 Segmented Rotor SRM for 60V Belt-Driven Starter Generator", Journal of Magnetics, Vol.21, No.3, 2016, pp.393398.

[25] B. G. Mecrow, "Fully pitched-winding switched-reluctance and stepping-motor arrangements", IEE Proceedings-B, Vol.140, No.1, 1993, pp.61-70.

[26] Md. A. Kabir, I. Husain, "Design of Mutually Coupled Switched Reluctance Motors (MCSRMs) for Extended Speed Applications Using 3-Phase Standard Inverters", IEEE Transactions on Energy Conversion, Vol.31, No.2, 2016, pp.436-445.

[27] W. Uddin, Y. Sozer, "Analytical modeling of Mutually Coupled Switched Reluctance Machines under saturation based on design geometry", IEEE Int. Conf. Electr. Machines \& Drives (IEMDC), 2015, pp.133-138.

[28] Y. H. Kima, S. Kimb, J. H. Choic, J. Ahnd, C. H. Choe, J. Lee, "Direct torque control of switched reluctance motor for minimizing torque ripple", International Journal of Applied Electromagnetics and Mechanics, Vol.28, no.(1-2), 2008, pp.247-253.

[29] T. Higuchi, T. Ueda, T. Abe, "Torque ripple reduction control of a novel segment type SRM with 2-steps slide rotor, IEEE Int. Conf. The International Power Electronics Conference (ECCE ASIA ), 2010, pp.2175-2180.

[30] P. C. Desai, M. Krishnamurthy, N. Schofield, A. Emadi, "Novel Switched Reluctance Machine Configuration With Higher Number of Rotor Poles Than Stator Poles: Concept to Implementation, IEEE Transactions on Industrial Electronics", Vol.57, No.2, 2010, pp.649659

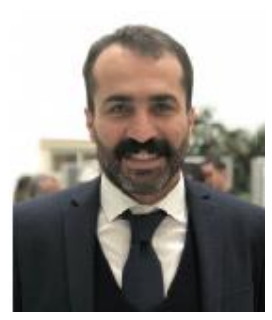

\section{BIOGRAPHIES}

CIHAN SAHIN was born İskenderun. He received B.S., M.S. and Ph.D degrees in Electrical Education from Kocaeli University, Kocaeli, Turkey, in 1999, 2007 and 2014 respectively. $\mathrm{He}$ is currently Asst. Prof. in Control and Automation Program of Vocational Scholl in Bilecik Şeyh Edebali University, Bilecik, Turkey. His research interests are automation systems (PLC, SCADA,etc...), power electronics and electric machines.

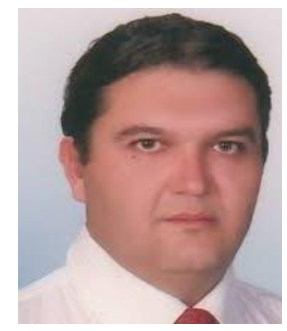

MEVLUT KARACOR was born Eskişehir. He received M.S. and the Ph.D. degrees in electrical education from Kocaeli University, Kocaeli, Turkey in 2004 and 2010 respectively. Since 2013, he has been working as an Asst. Prof. in Engineering of Mechatronic, Faculty of Technology, Manisa Celal Bayar University, Turkey. His research interests are automation systems (PLC, SCADA, etc...), power electronics and electric machines.

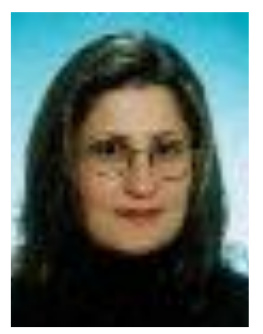

AYSE ERGUN AMAC was born İzmit. She received B.S. degree (with honors) in electrical education from Marmara University, Istanbul, Turkey in 1994 and the M.S. and the Ph.D. degrees in electrical education from Kocaeli University, Kocaeli, Turkey in 1997 and 2003 respectively. From 1995 to 2003, she was a research and teaching assistant in Department of Electrical Education, in Kocaeli University, Technical Education Faculty. From 2002 to 2004, she was in the Electric and Power Electronics Center and the Grainger Laboratories, Illinois Institute of Technology, Chicago as a research scholar to study on active filters and uninterruptible power supplies. Since 2014, she has been with the Energy Systems Engineering, Faculty of Technology, University of Kocaeli, as an Associate Professor. Dr. Amac's current research interests are hybrid electrical vehicles and computer based learning approaches in teaching power electronics courses. 